\title{
SOCIÉTÉ BELGE D'OTOLOGIE ET DE LARYNGOLOGIE.
}

Neeting, February 23 rd, 1896.

\author{
President-Dr. Delstanche.
}

\section{BAYER. A Case of Hard Chance of the Tonsil.}

A lady, aged twenty-two, consulted me regarding a tonsillitis of at least three weeks' duration, and which had been treated by a doctor by daily cauterization with nitrate of silver. The inflammation and the existence of ulceration appeared to me due to the repeated cauterizations ; I therefore recommended a simple palliative and antiseptic treatment. The ulcer cleaned up, but without showing any tendency to cicatrize, whilst the tonsil increased in size. At the same tme the glands became inflamed, causing rreat dysphagia and insomnia.

From these facts I concluded that the ulcer was syphilitic, and commenced mercurial inunction in the peritonsillar region. Improvement lesulted. The appearance of a characteristic roseolous rash soon after this left no doubt as to the nature of the affection, which improved rapidly under general treatment.

\section{EEMAN. A Case of Tracheotomy.}

A fortnight ago I had to perform tracheotomy for the following unusual conditions:-A man, aged fifty, suffered from an attack of gout (his first) in both feet. As this was passing off there arose suddenly pain in the right side of the neck, and rapidly increasing dyspnosa. I found phlebothrombosis of the right jugular, cedema of the right half of the larynx, extremely small glottic chink, dyspnoea intense and dangerous. Trachentomy rapidly performed. We were successful in recalling the soutr manifestations to the feet by mustard cataplasms ; aloes pills given.

The patient is now doing well, the phlebitis gradually disappearing: but prognosis must be very guarded on account of the danger of embolism.

This case may be compared with the not uncommon cases of acute phlebitis in gouty subjects in the saphenous and other large veins. Is it a unique case? So far I have been unable to find another recorded.

$$
\begin{aligned}
& \text { Eemax. Angina due to Streptococci, treated by Antistreptococic } \\
& \text { Serum. }
\end{aligned}
$$

In a case of angina due to streptococci, occurring in a child of four years old recovering from an eruptive fever, I applied the above treatment. I record the fact because I believe it is the first time this treatment has been used in Belgium. After pointing out the serious nature of these cases, Eeman went on to state that the use of the serum was perfectly successful, and that he intended to use it in future in cases of angina where pure streptococci are found, and to use it mixed with antidiphtheritic serum in cases where there is a mixture of streptococci 
and Loeffler's bacilli. At the same time he draws no conclusions from one case.

CHEval thought that Eeman exaggerated the dangers of streptococcic anginas; serious cases he considered exceptional.

Eexan. Nasai Diphtheria.

In Zarniko's "Diseases of the Nose" (Berlin, I894) it is stated that primary diphtheria of the nose remaining localized in the nose is extremely rare-if, indeed, it occurs. For some years I have held the opposite view, and latterly have observed at least half a dozen cases of primary nasal diphtheria not spreading to neighbouring parts. They have been carefully studied, both clinically and bacteriologically, the latter part of the investigation being carried out by my learned colleague, Van Emergen, and his assistant, Sugg.

These cases are peculiar in that they have no effect on the greneral health, and that their symptoms are those of a cold in the head, with blocking of the nose, much nasal discharge, and sometimes epistaxis. Recovery is spontaneous after a variable time, which may extend to some weeks. My first little patient was brought to me because for some days nasal respiration had appered to be difficult; no fever; general condition excellent. Nevertheless the thick membranes removed from the septum and fossæ contained Loeffler bacilli. Cultures from these were extremely virulent, killing like the most virulent preparations in the bacteriological laboratory. The other cases were all similar.

The importance of these cases is evident. They must act as centres for the diffusion of diphtheria both at home and at school. One case I treated with Roux's serum, and it appeared to me that its duration was markedly shortened. These cases have been so carefully studied that their genuineness is quite beyond dispute.

In the discussion following this paper Eeman's views were disputed by CAPART.

Hennebert. Temporal Caries. (Anatomical Specimen.)

I present the right temporal bone of an infant of two and a half years who died of acute enteritis, and who had suffered from a fœtid otorrhœa. Externally there is no sign of affection of the bone; no abscess, and the skin over mastoid and temporal regions is normal. At the autopsy I found necrosis of the tegmen tympani and upper wall of antrum. The meninges in this region were considerably thickened, and covered on their under surface by a caseous mass of the size of a hazel nut. All the retropharyngeal glands were enlarged and caseous, forming a chain that extended down into the mediastinum.

Hennebert. Epithelioma of the Temporal Bone.

This is a case from Prof. Delstanche's clinic, of a man aged thirty-eight.

When twelve years old he introduced into his left ear a piece of slatepencil, which was extracted only after detachment of the auricle. Union was not complete, and there remained a fistula in the auriculo-mastoid groove, from which there has been more or less abundant discharge of pus at intervals. 
Three months ago violent pains set in about the fistula, and the region around became infiltrated, this infiltration spreading rapidly upwards above the ear. At the same time complete loss of hearing.

The depth of the meatus was filled by a growth discharging pus and bleeding on the slightest touch. Delstanche operated. A horizontal incision six centimètres long, above the auricle, on the infiltrated area, revealed a fungating mass. This was curetted as thoroughly as possible, and left a cavity of the size of a hen's egg. Its inner limit was formed by the neninges (strongly driven inwards); its lower limit was formed by the pyramid of the petrous bone (the upper surface of which was largely destroyed); the other limits were formed by what was left of the squamous portion of the temporal. Histological examination: epithelioma. The point of greatest interest in this case was the complete absence of peripheral symptoms, in spite of the pressure on the meninges. Motion and sensation were normal, also the reflexes. No special symptoms in face or eyes, no alteration in the fundus of the eyes.

DELSTANChe thought the etiology was interesting. probably the cancer originated in the lesion produced by the slate-pencil.

\section{Roussedu. Turbinal Bulla (Cornet Ampullaire). (Anatomial} Specimens.)

I have here a beautiful specimen of the condition of the middle turbinated known as tur binal bulla, first described by Zuckerkandl. You see here the outer wail of the right nasal fossa, the septum having been removed. There are several lesions. The middle turbinated is considerably increased in size, cspecially at the anterior cxtremity. Here its measurements are: height 38 millimètres, thickness 18 millimètres, length 50 millimètres; whilst the average normal dimensions are 23 millimètres, 2 to 3 millimitres, and 38 millimètres. The superior and inferior turbinateds are atrophied, and the latter presents a deep depression in which lies the lower edge of the middle turbinated. A similar depression is found in the nasal process of the superior maxillary. The septum was strongly deviated to the left. We may therefore say that the middle turbinated completely filled the right nasal fossa. Mucous membrane normal.

On opening the middle turbinated we find a large ovoid cavity, closed all round. Its long axis (antero-posterior) measures twenty-three millimitres, the vertical and transwerse measurements being twenty-eight and fiftecn millimetres respectively. The walls are composed of threc concentric layers : ist, internal layer, a delicate membrane of connective thiste in process of organization, containing a large number of cmbryonic cells (Dr. D'Haenens); and, the middle layer, a bony envelope derived from the bony lamellat of the middle turbinated; 3rd, external layer, the normal mucous membrane of the turbinated. The cavity contains neither liquid nor tumour-nothing but air.

The present name for this condition, "cornet ampullaire," leaves out of account the contents of the cavity, and might well be replaced by the name "pneumatic turbinated," or "pneumatic hypertropby of the turbinated." I have here another specimen, sent by Dr. Hennebert, in 
which the contents are not air, but a myxoma; yet the name is the same.

SCHIFFers objected to the name "pneumatic hypertrophy of the turbinated," because the mucous membrane is normal.

CHEVAL proposed the name "pneumatic cyst of the turbinated."

LAURENT thought that the two cases might be destgnated similarly; thus :- "osseous aërial cyst" and " osseous myxomatous cyst of the middle turbinated."

CAPART asked what were the symptoms during life? Was there pus?

ROUSSEAU had not seen the case alive, and had no record of the symptoms. He had found no pus post mortem.

ROUSSEAU showed a specimen containing the "fourth turbinated" derived from the superior by division. In adults this was present in one out of every three (Zuckerkandl); more frequently according to his own researches. In the new-born it is constant (Moldenhauer), and generally disappears later, during the development of the ethmoid cells.

RUTTEN. Exostosis of the Right Meatus Auditorius. Remoral by means of Gouge. Recovery.

Osteomata of the auditory meatus appear sometimes as hyperostoses; more rarely are they pedunculated. They are then called "exostoses," or "enostoses" (Rokitansky). In consistence they vary from an ivory hardness to a spongy softness.

The exostosis that I now show you is extremely hard. It measures one and a half centimetres by one centimetre, has the form and size of a cherry-stone, and has scattered over its surface little rounded or flattened prominences which were buried in the carious walls of the meatus. These appeared during the operation to be so many points of attachment, but the real seat of origin was the postero-superior wall. This is the usual position; and as Prof. Politzer showed at the meeting of the Austrian Otological Society in $21 a y, 1895$, the mastoid process is almost always implicated, beins sometimes totally eburnated.

My patient was a man of thirty-eight years, who had never had discharge from the ear, and could only remember that he had once received a blow on the ear in his youth, from which he had suffered for some days. He first consulted me seren years ago for deafness in the right ear, and was much astonished when I made him feel, with his little finger, the hard body obstructing the meatus. He refused operation, although I pointed out the danger that might arise from suppuration at some future date.

Last month he again came to me, complaining of violent pain in the head, and slight foetid discharge from the ear. Hearing quite lost ; tuningfork on vertex referred to right ear. No swelling or tenderness over mastoid. With the gouge and mallet I removed the growth, and then ound that the walls of the meatus were necrosed, due to the pressure of the tumour.

The otorrlua in this case was the result, and not, as is usual, the cause, of the exostosis. This view is supported by the fact that the patient had never had any subjective symptoms in the car, not even itching: and further by the facts that after removal of the exostosis the hearing was 
almost perfectly restored, the osteo-periostitis of the meatus disappeared, there was no implication of the mastoid, and the otorrhea ceased. Aftertreatment consisted in continuous irrigation with boracic solution, and later in iodoform dressings. Arthur J. Hutchison (Trans.).

\title{
OX F ORD MEDICAL SOCIETY.
}

Heeting, February 14th, 1896. ("Brit. Med. Journ.," Felmuay 29th, I896.)

\author{
President-Prof. BuRDON SANDERSON.
}

Dr. F. A. Dixey. Vital Statistics of Diphtheria in London, I891-95.

The author pointed out that for some years past the death rate from diphtheria in London had shown a marked increase. With regard to the influence of school attendance, his statistics indicated diminished opportunity for contagion during the holidays, with renewed activity after reopening. In their bearing on the antitoxin treatment the figure showed an increase in the prevalence of the disease, with a considerable diminution in the mortality. It was difficult to escape the conclusion that the late lowering of mortality was due to generalization of the new method of treatment.

Ernest Waggett.

\section{PATHOLOGICAL SOCIETY OF MANCHESTER.}

Hecting, February 12th, I896. ("Brit. Med. Journ.," February 29th, 1896.)

$$
\text { President-H. R. Hutron, M.B. }
$$

Dr. HARING. 1 Case of Sarioma presenting in tia Nisal Fossa.

$A$ case of a female of twenty-six, in whom, four months after removal of a polypus, apparently of ordinarily benign character, the right nasal cavity was found to be blocked by a round-celled fibro-sarcomatous srowth. After intranasal operation and repeated curetlage during six months, it became necessary to remove the body of the ethmoid by external operation. The apparently benign polypus first noticed was probably produced by irritation on the surrounding tissues by the malignant neoplasm.

Ernest lingrett.

\section{WIENER MEDIZINISCHE CLÜB.}

Meeting, February I2th, 1896.

HACk. A Case of My'diema and a Case of Idiocy in Fonr-year-old Children. Under thyroid treatment the myxoedema was cured. The case of idiocy improved. 